\title{
Characteristics of Water Quality and Biological Changes in the Onchun Stream -After the Flowing of the Nakdong River-
}

\author{
Hong-Ki Park ${ }^{1}$, Jung-Won Son ${ }^{2}$ and Jin-Tack Choi ${ }^{1}$ \\ ${ }^{1}$ Water Quality Institute, Water Works HQ of Busan Metropolitan City, Kyoungnam 621-813, Korea \\ ${ }^{2}$ Busan Metropolitan City Institute of Health and Environment, Busan 613-806, Korea
}

Received May 16, 2012 /Revised August 7, 2012 / Accepted August 9, 2012

\begin{abstract}
This study investigated the changes caused by diverting water applications at the riverhead of the Onchun Stream via the monitoring of several water quality and biological parameters between 10/09 and 10/10. The analysis indicated that the Onchun Stream distinctly decreased in terms of several water quality parameters, such as BOD, COD, TN, TP, and the concentration of heavy metals as compared to similar values in 2005, before the flowing of the Nakdong River. Especially, BOD showed the 2nd grade of water quality, with an average of $2.0 \mathrm{mg} / \mathrm{l}$ at all sites. The species number and standing crops of plankton and benthic macroinvertebrates in the Onchun Stream were also increased. Thus, it was concluded that diverting water from the Nakdong River to the Onchun Stream dramatically improved various environmental indices, such as water quality and biological changes.
\end{abstract}

Key words : Water quality, biological parameters, plankton, benthic macroinvertebrates

\section{서 론}

하천은 산, 평야, 해산, 섬 등과 같이 국토 환경의 주요 구성 요소이며 육역과 해역으로 구성된 국토 중에서 육지부의 수역 이다. 하천은 물과 흙으로 구성되어 있기 때문에 흙만으로 구 성된 육역이나 물만으로 구성된 해역과 달리 독특한 생태 서 식처를 구성한다[6,7] 경관생태 측면에서 하천은 물길인 하도 와 하도를 따라 형성된 회랑으로 형성된다. 자연 하천의 형태 는 기본적으로 하도, 홍수터 또는 범람원, 자연 제방과 배후 습지로 나타난다. 하천의 형태는 그 속에 사는 동식물의 서식 처 특성을 지배한다. 회랑은 하도를 따라, 바탕은 홍수터에나 배후 습지에, 경관생태 조각은 하천의 형태가 급격히 변하는 곳에 많이 나타난다. 하천은 지표수가 모여서 중력에 의해 높 은 데서 낮은 데로, 단기간에는 변하지 않는 비교적 일정한 곳을 따라 흐르는 자연의 '물길'이다.

성장우선시대의 하천관리는 도시화에 따라 하천유역에서 의 토지이용과 생산활동이 증대되면서 치수와 이수 목적의 대규모 공사 진행에 의해 하천환경이 크게 훼손되어 하천이 지닌 고유한 자연환경 기능이 저하되면서 하천의 수질오염 확대, 소하천의 건천화, 하천공간의 황폐화 등으로 하천본래 의 환경기능은 상실하게 되어 생물이 살 수 없는 단순 하수도 전락하게 되었다. 그러나, 경제발전으로 생활에 여유가 생기 면서 하천환경에 대한 관심이 높아지고 훼손된 하천을 원래의 자연스러운 하천생태에 가깝게 복원하여 하천을 시민의 휴식

\footnotetext{
${ }^{*}$ Corresponding author

Tel : +82-51-669-4643, Fax : +82-51-669-4669

E-mail : phk111@korea.kr
}

공간으로 이용하고자 하는 요구가 늘어나고 있으며 이 요구에 대한 결과는 자연형 하천의 복원으로 가시화되어 가고 있다. 이미 선진국에서는 하천과 관련된 생태적 복원운동과 복원사 업 등이 수행되고 있다. 특히 독일, 오스트리아, 스위스 등에서 는 1970년대부터 이른바 근자연형 하천공법이라 하여 기존의 콘크리트나 금속 등 전통적인 토목 재료 대신에 갯버들, 풀 등 살아 있는 생물 재료와 거석, 통나무 등 자연 재료를 이용하 여 하천 사업을 하기 시작하였다[7]. 이러한 외국의 자연형 하 천 개념에 대해 국내에서도 그 필요성에 대한 공감대가 형성 되어 훼손된 자연환경을 재생 및 보곡하고자 하는 시도 및 연구가 이루어지고 있다.

부산시의 대표적 도심하천인 온천천은 금정산 고단봉에서 발원하여 유로 $14.85 \mathrm{~km}$ 를 형성하면서 도심 밀집 주거지역을 관류하는 지방 2 급 하천으로 하상경사가 심하며 14 개의 지천 으로 구성되어 있다[6,7]. 지난 10 여년간 다수의 계획이 수립 되어 하천정비를 추진해 오면서 주로 치수기능을 고려한 원활 한 유수를 위하여 저수로를 콘크리트라이닝으로 하여 하천환 경을 악화시켜 생물이 살지 못하는 죽은 하천이었으나 1999년 부터 온천천 유역에 콘크리트 하천바닥을 걷어내는 등 자연형 하천 복원사업을 시작하여 하수관거를 정비하고 자연형 하천 공법을 적용한 다양한 호안기법과 수질정화를 위한 접촉산화 법 등이 적용되어 하천환경이 개선되어 최근 많은 시민이 이 용하고 있으나, 갈수기에는 하수차집에 따라 하천유지용수 절 대 부족 현상으로 자연형 하천의 기능을 상실하고 있다. 건전 한 생태계와 쾌적한 환경유지를 위해 2005년 11월부터 낙동강 물을 온천천 유지용수로 공급하여 수질개선 및 생태복원을 추진하고 있다. 이러한 낙동강 원수에는 도수관 속 조개류 부 
착방지 등을 위해 염소를 미량 주입하고 있는데 2009년 6월 염소처리 된 낙동강 원수의 온천천 공급으로 하천 생태계에 영향을 준다는 환경운동연합의 중단 요청이 있었다. 그리고 2009년 7월 생태영향에 대해 검토하라는 시장훈시(121호)가 있어 염소처리된 낙동강 원수가 하천유지용수로 공급되고 있 는 온천천을 정기적으로 조사하여 생태계 영향 여부를 확인하 고자 하였다.

따라서 본 연구는 온천천의 수질 및 생물계가 유지용수 공 급 전, 후 어떠한 변화가 있는지를 확인하기 위하여 이화학 및 생물학적 항목 등을 조사 및 평가하여 물 환경평가의 기초 자료로 활용하고자 하였다.

\section{재료 및 방법}

\section{조사지점 및 기간}

본 연구는 낙동강 원수가 유입되기 전인 온천천 상류지점인 청룡2호교, 낙동강원수가 유입된 직후 지점인 남산 본동교, 중류지점인 신암교 - 금정구청 그리고 하류지점인 세병교 등 5 개 지점을 선정하여 2009년 10월부터 2010년 10월까지 실시 하였다. BOD 등 원수 수질항목은 월 1 회 실시하여 총 12 회, 플랑크톤 항목은 총 8 회, 저서성 대형 무척추 동물 및 하상 퇴적물 중금속 항목은 분기별로 총 4 회 분석하였다.

\section{이화학 및 미생물학적 조사}

수온, $\mathrm{pH}$ 및 용존산소는 현장 측정기(Orion, Model 260)로 현장에서 바로 측정하였으며 $\mathrm{BOD}, \mathrm{COD}, \mathrm{TP}, \mathrm{TN}$ 등은 시료 채취 후 즉시 실험실로 운반하여 수질오염공정시험방법에 따 라 분석하였다[1]. Chlorophyll 농도는 $500 \mathrm{ml}$ 의 시료를 0.45 $\mu \mathrm{m}$ filter로 여과시킨 후 $90 \%$ acetone 용액에서 24시간 chlorophyll을 추출하였다. 이때 chlorophyll의 불안정화를 막기 위 하여 포화 $\mathrm{MgCO}_{3}$ 용액으로 세척하였다[1]. 추출된 용액을 $4,000 \mathrm{rpm}$ 에서 10 분간 원심분리한 후 상등액을 취해 각각 750 , $664,647,630 \mathrm{~nm}$ 에서의 흡광도를 측정하여 trichromatic method (APHA, 1992)의 계산식에 따라 chlorophyll-a의 양을 계산하였다. 총대장균군(Total coliforms) 실험은 막여과법을 이용하여 실시하였다. 시료 $100 \mathrm{ml}$ 를 $0.45 \mu \mathrm{m}$ filter로 여과시 킨 후 $\mathrm{m}$-Endo LES 한천배지에 옮겨 $35^{\circ} \mathrm{C}$ 배양기에서 1 2일 배양한 후 총대장균군 검출여부를 확인하였다[9,10].

\section{식물 및 동물플랑크톤 조사}

식물플랑크톤 동정은 채수한 표층수 11 를 $15 \mu \mathrm{m}$ 체로 걸러 최종적으로 $20 \mathrm{ml}$ 되게 농축한 후, 중성 포르말린 1 2 $\mathrm{ml}$ 로 고정하여 Sedgwick-Rafter chamber로 계수하였으며 ml당 세 포수로 환산하여 현존량으로 표시하였다. 동물플랑크톤 동정 은 한국담수동물플랑크톤도감의 분류체계를 따랐으며, 섬모 충류의 분류는 문 등의 체계 등을 참고하였다[4,5].

\section{중금속 조사}

시료채취는 모종삽으로 채취하여 폴리에틸렌 봉지에 담아 밀봉한 후 실험실로 운반하였으며 전처리는 토양오염공정시 험방법에 의하여 시료를 통풍이 잘 되는 곳에서 건조시킨 후 $2 \mathrm{~mm}$ 표준체(10메쉬)에 통과한 시료를 분석용 시료로 하여 구리, 망간 등 6개 항목을 원자흡광광도계를 이용하여 분석하 였다[12].

\section{저서성 대형 무척추동물 조사}

저서성 대형 무척추동물 채집은 계류용 정량 채집망인 suber net $(30 \times 30 \mathrm{~cm}$, 망묵 $0.5 \mathrm{~mm})$ 을 사용하여 각 조사지점 에서 가능한 미소서식처(riffle, run, pool)를 구분하여 3회씩 정량 채집하였다. 채집된 표본은 현장에서 $10 \%$ 포르말린으 로 고정하여 실험실로 운반한 후 sorting하여 $10 \%$ 에탄올에 보관하였으며 Merrit and Cummins 등을 참조하여 실시하 였다. 종 수준까지 분류가 어려운 종은 외부형태가 확연히 구별되는 종을 대상으로 임의로 과나 속 수준에서 $\mathrm{sp} \mathrm{1.} \mathrm{등의}$ 형태로 정리하였다. 저서성 대형 무척추동물의 군집구조를 파악하기 위해 채취시기 및 지점별로 개체수와 종수, 종다양 성지수 그리고 한국오수생물지수를 비교하였다. 종다양성지 수는 Shannon-wiener function에 따라 산출하였으며, 한국 오수생물지수는 환경부에서 개발한 기준표를 참고로 하여 실시하였다[8,14].

\section{결과 및 고찰}

\section{온천천의 수질변화}

먼저 지점별 평균 농도는 Fig. 2와 같이 중하류 지점으로 내려갈수록 농도가 증가하였으며, 년도별 수질변화는 전체적 으로 개선되는 것으로 나타났다. 유지용수 공급 후 대표적 원 수 수질항목인 $\mathrm{BOD}$ 의 경우 유지용수 공급 이전인 2005년 평 균 $5.5 \mathrm{mg} / 1$ 이었으나 이번 조사에서는 평균 $2.0 \mathrm{mg} / 1$ 으로 나 타나 2급수를 유지하는 것으로 나타났다. 영양염류인 총인의 경우 2005 년 $5.0 \mathrm{mg} / 1$ 에서 2010 년 $2.73 \mathrm{mg} / 1$ 으로, 총질소는 2005년 $0.3 \mathrm{mg} / 1$ 에서 2010 년 $0.08 \mathrm{mg} / 1$ 으로 나타나 각각 $45.4 \%$ 와 $73.3 \%$ 감소한 것으로 조사되었다[6]. 그리고 $\mathrm{pH}, \mathrm{DO}$ 등 다른 원수 수질항목도 하천 생활환경 기준에서 약간 좋음 (ㅍ)을 유지하고 있어 수질이 전반적으로 개선되었음을 알 수 있었으며, 잔류염소는 모든 지점에서 검출되지 않았다

\section{온천천의 하상 퇴적물(저질) 중금속 변화}

중금속은 수역의 오염상태를 반영하는 오염지표로서 점토 표면의 금속산화물과 공침하고 있다가 지천의 자연, 물리, 화 학적 영향에 의해 상부의 수층으로 장기간에 걸쳐 용출되어진 다[11,13]. 농도변화를 살펴보면 원수 수질항목과 마찬가지로 중하류 지점으로 내려갈수록 농도가 증가(Fig. 3)하였으며, 이 


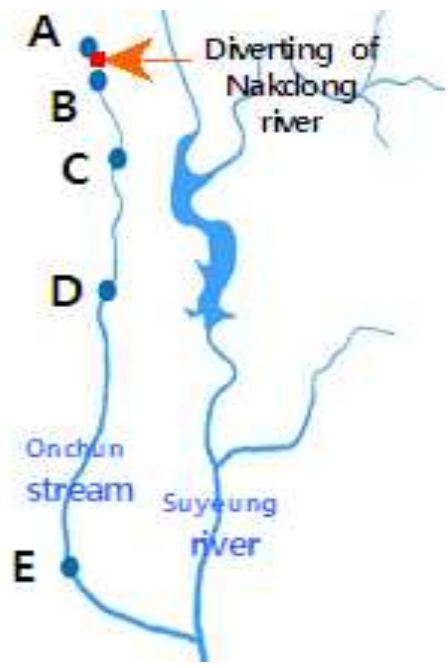

Fig. 1. Map of the Onchun stream showing sampling sites. A: Chungyong Bridge, B: Bondong Bridge, C: Shinarm Bridge, D: Gumjunggu Official, E: Saebaeng Bridge
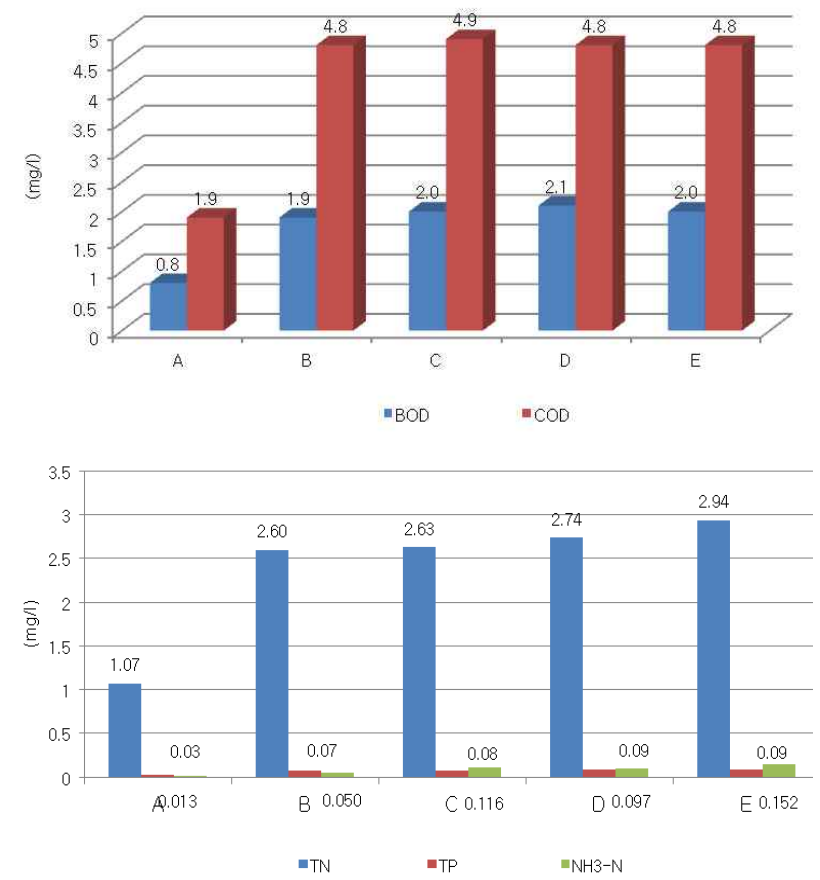

Fig. 2. Monthly variation factor of water quality sampling sites. A: Chungyong Bridge, B: Bondong Bridge, C: Shinarm Bridge, D: Gumjunggu Official, E: Saebaeng Bridge.

번 조사결과는 2007년에 비해 다소 증가한 것으로 나타났는데 [7] 이는 지천인 사직천의 합류식 하수관거의 생활하수, 이물 질 등의 비점오염원이 강우에 의해 월류하여 유입되어 증가한 것으로 판단된다[6]. 특히 망간 농도가 다른 중금속에 비해 높 은 농도를 보였는데 이는 지질에 기인하며, 토양이나 저질에 서 망간은 이산화망간으로 존재하고 있는데 혐기성 상태에서 망간 4 가가 망간 2 가로 환원하여 쉽게 용해가 되기 때문인

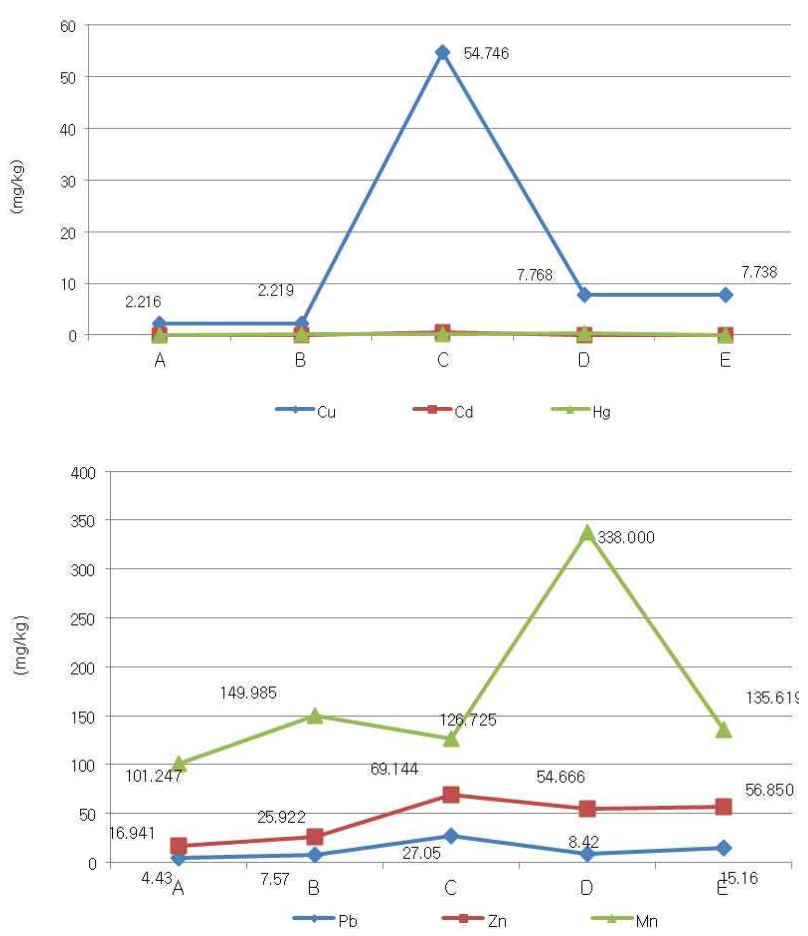

Fig. 3. Average concentration of Ignition loss heavy metals in the sediment of Onchun stream during the study. A: Chungyong Bridge, B: Bondong Bridge, C: Shinarm Bridge, D: Gumjunggu Official, E: Saebaeng Bridge.

것으로 추측된다. 그러나 평균 농도는 미국 $\mathrm{EPA}$ 저질기준인 $400 \mathrm{mg} / \mathrm{kg}$ 보다는 낮은 것으로 나타났으며[2], 타 지역인 경기 도 신천 저질의 $439 \mathrm{mg} / \mathrm{kg}$, 안양천 퇴적물 $725 \mathrm{mg} / \mathrm{kg}$ 보다도 훨씬 낮은 수준이어서 온천천 저질은 대체로 양호한 것으로 나타났다.

\section{온천천의 식물 및 동물플랑크톤 변화}

먼저 식물플랑크톤의 경우 규조류(77.7\%)가, 동물플랑크톤 은 윤충류(65.2\%)가 우점하는 것으로 조사되었다. 식물플랑크 톤 출현종수는 2005년 평균 20종에서 2010년 평균 43종으로 나타나 2배 정도 증가한 것으로 나타났다. 그리고 이번 조사결 과 확인된 식물 및 동물 플랑크톤은 2005년 5급수에 서식하는 오염 지표종에서 2010년 2급수에 서식하는 낙동강 출현 종으 로 변화한 것으로 나타나 수중 생태계가 상당히 개선되었음을 알 수 있었다.

\section{온천천의 저서성 대형 무척추동물 군집변화}

저서성 대형 무척추동물은 종류가 매우 다양하고 환경조건 에 따른 적응성이 좋으며, 이동성이 적고 서식처의 환경교란 에 대하여 민감하게 반응하며, 정량적인 채집과 분석이 용이 하므로 이를 이용한 수질환경 조사가 활발하게 이루어지고 있는 추세이다[3]. 조사결과 저서성 대형 무척추동물 항목 조 

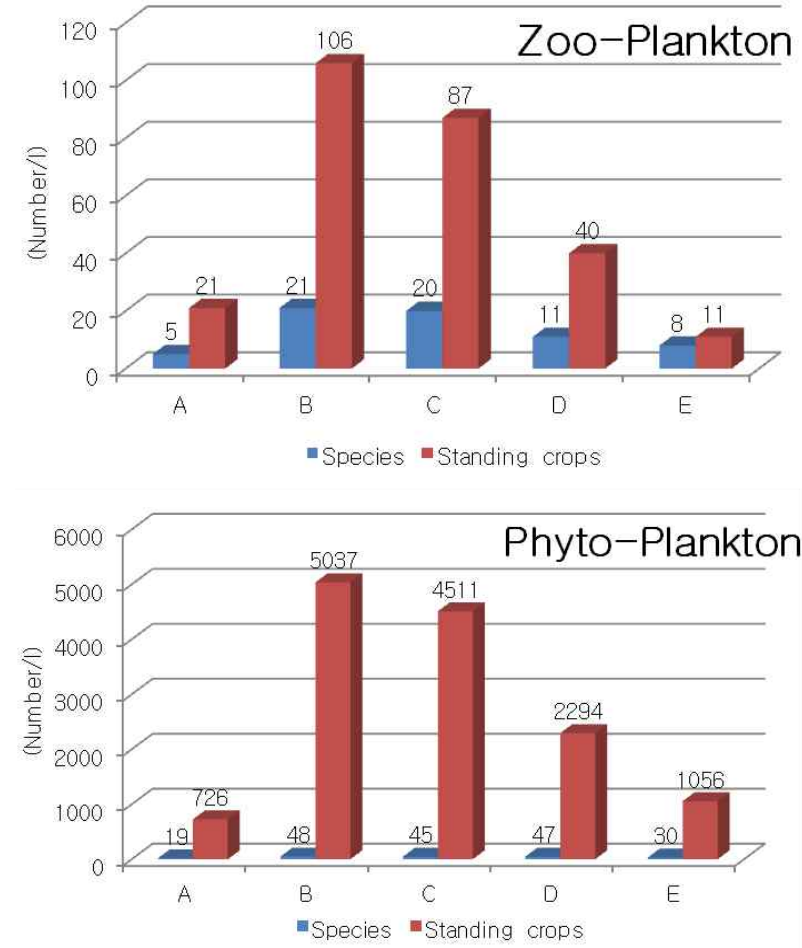

Fig. 4. Number of species and standing crops of plankton in the Onchun stream. A: Chungyong Bridge, B: Bondong Bridge, C: Shinarm Bridge, D: Gumjunggu Official, E: Saebaeng Bridge.

사에서는 개체수가 절지동물문의 경우 $57 \%$ (42종), 환형동물 문이 $36 \%$ (3종) 차지하는 것으로 나타났으며, 개똥 - 무늬 하 루살이, 플라나리아 그리고 깔따구류가 다수 출현하는 종으로 조사되었다. 그리고 세병교(하류)지점에서 개체수가 급속히 증가한 것을 알 수가 있었는데 이는 오염지표종인 실지렁이 번식에 기인한 것으로 보여지는데 이러한 원인은 세병교 인근 사직천의 하수관거 중의 생활하수 등의 비점오염원이 강우시 월류 유입하여 저질의 생태환경을 악화시킨 것으로 보여진다 (Fig. 5). 서식 종은 2005년 평균 2종에서 2010년 평균 23종으로 생태계가 유지용수 공급전에 비해 약 10 배 정도 증가하였다. 생물환경지수(GPI)는 종의 풍부도(다양성)와 균등도, 안정성 을 나타내는 지수로 값이 클수록 종 다양성이 높고 양호한 생태계를, 한국오수생물지수(KSI)는 환경부에서 개발한 생물 학적 하천 수질평가지수로 수질이 악화될수록 큰 값을 나타낸 다. 이번 조사결과 온천천은 Fig. 6 과 같이 세병교를 제외한 모든 지점의 생태계가 양호한 수준인 것으로 나타났다.

이번 조사결과에서는 미량 주입된 잔류염소가 관로내에서 대부분 소실되어 종다양성 등 생태계에 대한 악영향은 관찰되 지 않았지만 잔류염소는 유해물질이므로 하천에 유입되지 않 도록 지속적인 모니터링이 필요할 것으로 생각된다. 또한 낙 동강 원수의 유입으로 온천천의 생태학적 특징이 전반적으로 개선되었으나 동래구, 연제구 구간의 온천천 수계는 도심지에

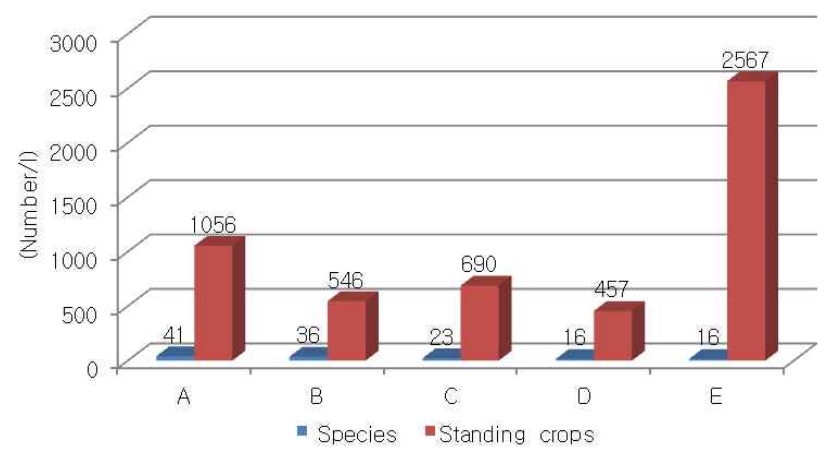

Fig. 5. Total individuals and species of macroinvertebrate during the study period in the Onchun stream. A: Chungyong Bridge, B: Bondong Bridge, C: Shinarm Bridge, D: Gumjunggu Official, E: Saebaeng Bridge.

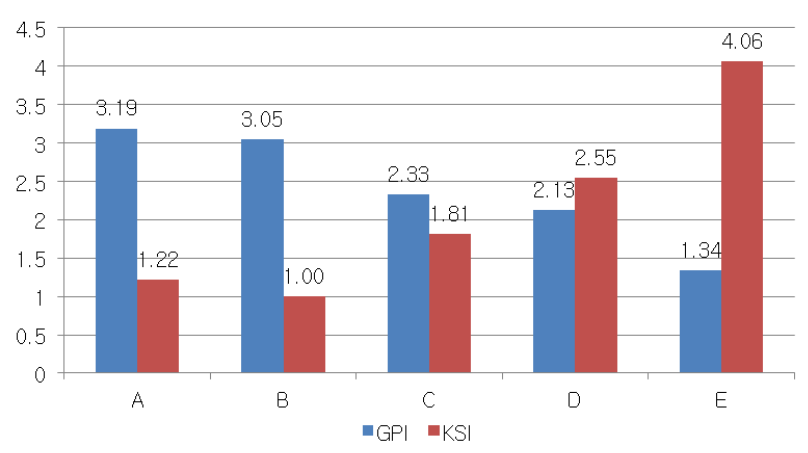

Fig. 6. Variation of GPI and KSI at each site during the study period in the Onchun stream. A: Chungyong Bridge, B: Bondong Bridge, C: Shinarm Bridge, D: Gumjunggu Official, E: Saebaeng Bridge.

위치하고 있어 강우시 비점 오염원 등의 간헐적 유입으로 인 해 생태학적 뚜렷한 개선이 더딜 수도 있다[2]. 따라서 온천천 의 지속적인 물 환경 개선을 위해서는 하류 지천에 산재해 있는 하수관거를 합류식에서 분류식으로의 변경하는 정비를 지속적으로 실시하여야 할 것으로 판단된다.

\section{References}

1. APHA. 1992. Standard Methods for the Examination of Water and Wastewater. APHA-AWWA-WPCF, New York.

2. EPA. 2000. Summary of Sediment Quality Guideline.

3. Hellawell, J. M. 1986. Biological Indicators of Freshwater pollution and Environmental Management, Elsevier, London and New York, pp. 546.

4. JO, K. S. 1993. Illustration of The Freshwater Zooplankton of Korea, Academy pub, Co, Seoul.

5. Jung, J. 1993. Illustration of The Freshwater Algae of Korea, Academy pub, Co, Seoul.

6. Kwon, D. M and Son, J. W. 2006. Characteristics of Aquatic Environment in Onchun Stream-Before and After the 
Flowing of Nakdong River-. The Annual Report of Busan Metropolitan City Institute of Health and Environment. 16, 94-104.

7. Kwon, D. M and Yoo, E. H. 2007. Characteristics of Aquatic Environment in Close-to-Nature Onchun Stream. The Annual Report of Busan Metropolitan City Institute of Health and Environment. 17, 63-75.

8. Merritt, R. W and Cummins, K. W. 1996. An Introduction to the Aquatic Insects of North America, 3rd, ed, Kendall/Hunt Pub, Co. pp. 862.

9. Ministry of Environment. 2002. Standard for Drinking Water
Treatment.

10. Ministry of Environment. 2002. Standard Method for the Drinking Water Quality.

11. Ministry of Environment. 2002. The result of Soil point and Distribution, pp. 3-11.

12. Ministry of Environment. 2009. Standard Method for the Soil Pollution.

13. National Institute of Environmental Research, 2000. A Study on the Seasonal characteristics of Stream water quality.

14. Won, D. H. 2005. Aquatic Insects of Korea, Korea Ecosystem Service, Seoul.

\section{초록 : 낙동강 유지용수 공급 후 온천천의 수질 및 생물변화 특성}

박홍기 ${ }^{1} *$ 손정원 ${ }^{2} \cdot$ 최진택 $^{1}$

(부산광역시 상수도사업본부 수질연구소, ${ }^{2}$ 부산광역시 보건환경연구원)

낙동강 유지용수가 공급되고 있는 온천천을 대상으로 2009년 10월부터 2010년 10월까지 수질 및 생물학적 인자 변화를 조사하였다. 조사결과 온천천은 $\mathrm{BOD}, \mathrm{TN}, \mathrm{TP}$ 그리고 중금속 농도가 낙동강 유지용수가 공급되기 이전인 2005년에 비해 뚜렷하게 감소한 것으로 나타났으며, 특히 BOD 평균농도가 $2.0 \mathrm{mg} / 1$ 로 모든 지점이 2급수를 유지하 였다. 또한 온천천 수중에 존재하는 플랑크톤과 저서성 대형 무척추동물의 종 및 개체수도 증가한 것으로 조사되었 다. 결론적으로 낙동강 유지용수가 공급된 이후에 온천천은 수질 및 생물변화와 같은 물 환경인자가 상당히 개선되 었음을 알 수 있었다. 